\title{
Knowledge, Attitudes and Practices Regarding Cervical Cancer Screening Among Village Health Volunteers
}

\author{
Siriwan Srisuwan', Pawin Puapornpong ${ }^{1}$, Supattra Srisuwan², Kornkarn \\ Bhamarapravatana $^{3}$, Komsun Suwannarurk ${ }^{4}$
}

\begin{abstract}
Background: In the years 2014, coverage rates of cervical cancer screening in Nakornnayok province accounted to $76.5 \%$. This was lower than the government's specified goal of $80 \%$. Community health volunteers are members of a Thai healthcare alliance established to help promoting healthcare service communication and collaboration at the primary level. Such village health volunteers (VHVs) are established in most villages. Objective: To assess the knowledge and attitudes of cervical cancer screening among VHVs. Materials and Methods: The subjects were 128 VHVs from four Nakornnayok sub-districts; namely Klong Yai, Chomphol, Buangsan and Suksara, Thailand. The study was conducted from December 2014 to January 2015. The questionnaire was designed to assess the knowledge and attitude of cervical cancer screening provided by the VHVs. In addition, cervical cancer screening coverage rates of each area were collected. The demographic data, scores of knowledge, attitudes, practices and the cervical cancer screening coverage rates were analyzed by one-way ANOVA. Results: The questionnaire reliability was assessed as 0.81 . The total knowledge and attitude scores were 10 and 15 points. The mean knowledge scores of KlongYai, Chomphol, Buangsan and Suksara were 6.8, 7.0, 6.5 and 9.0 points, respectively. The VHVs had a high level of overall knowledge about cervical cancer screening. The mean attitude scores were 12.4, 13.2, 13.4 and 13.1 points. VHVs had a positive attitude to the promotion of cervical cancer screening at the overall level. The percentages of VHVs promoting cervical cancer information in respective districts were 72.2, 94.3, 94.9 and 50.0. However, the cervical cancer screening coverage rates were $62.4 \%$, $34.7 \%, 80.3 \%$ and $47.3 \%$ respectively. Conclusions: The knowledge, attitudes and percentages of promoting information of cervical cancer screening among VHVs in the four sub-districts were high but did not correlate with the cervical screening coverage rates for each area. VHVs needed to understand socio-cultural beliefs of the women in the target population and design suitable strategies to encourage higher cervical screening coverage.
\end{abstract}

Keywords: Cervical screening - knowledge - attitudes and practices - village health

Asian Pac J Cancer Prev, 16 (7), 2895-2898

\section{Introduction}

Cervical cancer is the most common gynecologic cancer worldwide. It is the second most common cancer among women in Thailand. The common age group of patients was 45-55 year (Wilailak, 2009). Papanicoloau (Pap) smear is the principle method for cervical cancer screening. The Thai universal healthcare policy under the guidance of Thai Ministry of Public Health recommended that Thai women aged 30 to 60 years old should be screened for cervical cancer at least every five years by any methods (The $11^{\text {th }}$ National Economic and Social Development Plan, 2012-2016). These methods included Pap smear, visual inspection with acetic acid (VIA) and human papilloma virus (HPV) testing.
The goal is to achieve the coverage rate of screening tests up to at least 80 percent among the target women. Provincial Public Health policy of Nakornnayok, a province north of Bangkok, recognized the importance of cervical cancer screening. The office set a 80 percent goal for Pap smear cervical cancer screening for women residences aged 30-60 years-old. In 2014, only $76.51 \%$ women attended cervical cancer screening program in Nakornnayok. The number was lower than the specified goal. Coverage rates of cervical cancer screening in Mueang, Ban Na, Ongkharak, PakPhli districts were $75.34,83.75,70.96$ and 71.61 , respectively. These data indicated that the coverage rates of screening in Ongkharak districts was the lowest. VHV is a system composed of health volunteer liaison providing health

${ }^{1}$ Gynaecologic Oncology Unit, Department of Obstetrics and Gynaecology in HRH Princess Maha Chakri Sirindhorn Medical Center, Faculty of Medicine, Srinakharinwirot University, Nakornnayok, ${ }^{2}$ Department of Agricultural Extension and Communication, Faculty of Agriculture, Kasetsart University, Bangkok, ${ }^{3}$ Department of Preclinical science, ${ }^{4}$ Gynaecologic Oncology Unit, Department of Obstetrics and Gynaecology, Faculty of Medicine, Thammasat University, Pathumthani, Thailand *For correspondence: khunnuyai@ hotmail.com 
information and necessary basic health service to villagers. The volunteers are normal layman who receives organized health information from public health personals.

Nurses from sub district health unit are responsible for educating VHV with knowledge and necessary operating procedure including surveillance and prevention of interested health topics. Level of health knowledge, their positive attitudes toward cervical screening and cervical screening promotion creativity of VHVs in conjunction with level of success cervical screening were the subject of this research interest. We wanted to see if VHV knowledge and attitude has any contribution to successful cervical screening rate.

\section{Materials and Methods}

This was a cross sectional study. The data were collected from 128 volunteers between December 2014 to January 2015. Inclusion criteria were VHVs who had responsibilities in the area of Klong Yai, Buangsan, Chomphol and Suksara sub-districts of Ongharak, Nakhonnayok province, Thailand. Exclusion criteria were; VHVs who had severe illnesses and not actively volunteering or were not willing to participate in this research. The questionnaire on health knowledge, volunteer's attitudes and cervical cancer promotion practices was created. The validity of the questionnaire has been tested by 10 medical personals in community medicine and health promotion. The reliability of the questionnaire was tested by the distribution of the questionnaire to $10 \mathrm{VHVs}$. The results were calculated by Cronbach's alpha. Next, The revised questionnaire was then distributed to VHS and later returned. Ten questions regarding the knowledge of cervical cancer screening were included in the questionnaire in a true or false format. If the VHVs chose the right answer they scored 1 point and a wrong answer scored a zero. Three questions surveyed the VHV's attitude using a five-level Likert system; 1. Strongly disagree, 2. Disagree, 3. Neither agrees nor disagree, 4. Agree and 5. Strongly agree.

Knowledge and attitude scores, percentage of practices were then analyzed for any correlation found between the studied factors and cervical cancer screening coverage rates in the community. An in depth interview was conducted with ten randomly chosen local participants to reveal how their cervical cancer screening decision were made. Cervical cancer screening coverage rates were obtained from each sub district data. The demographic data, knowledge, attitude scores, practice score and the cervical cancer screening coverage rates were analyzed by means, percentages, standard deviations and one way ANOVA tests. A p-value less than 0.05 were considered statistically significant. Statistical analysis was performed using SPSS software (version 19.0, SPSS Incorporated). The sample size was calculated based on Yamane 's formula. By using Yamane 's formula of sample sized with error 5\%. The calculated sample size was 128 .

This present study was approved by the Ethical committee of the Faculty of Medicine, Srinakharinwirot University.

\section{Results}

The validity of questionnaire was tested by 10 experts in related fields. The reliability was at 0.81 . Of the 128 village health volunteers that had been enrolled; 48, 39, 29 and 12 were from KlongYai, Buangsan, Chomphol and Suksara, respectively. Mean age of VHVs was 46.77 years old. Female and male ratio was 93:7. The married, divorced or separated and single VHVs were 78.25, 11.82 and $9.92 \%$, respectively. Eighty nine percent of them were without college degrees and $10.2 \%$ held either a bachelor's or master's degree. The details are shown in Table 1.

A total of $60 \%$ of the female VHVs recently had Pap smear screening. The VHVs had a high level of knowledge about the cervical cancer screening in the overall mean score of 0.70 points (Table 2).VHVs had positive attitudes to the promotion of cervical cancer screening in the overall mean score 4.31point. The scores regarding health knowledge, health attitude, health practice, cervical cancer screening coverage in each area are presented as percentages and p-values in Table 4. Health knowledge, health attitude and cancer screening promotion of VHV were not associated with total Cervical Cancer Screening in their responsible district/subdistrict (Table 4).

An in depth interview was also conducted with ten local participants who were willing to provide more detail about how their cervical cancer screening decision were made. Main barriers to screening were embarrassment, poor attitude, conflict, beliefs and socio-cultural. In Chomphol sub district, $95 \%$ of the target population were Muslim women. They held themselves strictly per the socio-cultural rule. Thai Muslim women were worried that the village Pap smear conducting area was not providing a total privacy. They were bothered by the fact that the Pap test was perform to their private body parts by VHV who lived in the same village. They did not want to have their private part seen by their neighbors. Married women were not allowed to receive a Pap test without their husbands permission. As a result another screening barrier was their husbands' information and attitude toward this screening. In Suksara sub district, the

Table 1. General Characteristics of VHVs in 4 PCU of Nakornnayork, Thailand

\begin{tabular}{lc}
\hline Mean age (years) & 46.77 \\
\hline Sex* & \\
$\quad$ Female & 73 \\
$\quad$ Male & 7 \\
Education* & 89.8 \\
$\quad$ Less than college degrees & 10.2 \\
$\quad$ Equal or more than college degrees & \\
Income (Baht)* & 45.3 \\
1,000-10,000 & 16.4 \\
10,001-30,000 & 1.6 \\
30,001-50,000 & 36.7 \\
Unknown & 12.5 \\
Marital status* & 74.2 \\
$\quad$ Single & 13.3 \\
$\quad$ Married & Widow\&divorced \\
*percent; VHVs: village health volunteers; PCU: primary care unit
\end{tabular}




\begin{tabular}{|c|c|c|c|c|c|}
\hline \multirow[t]{2}{*}{ Knowledge scores } & \multicolumn{2}{|c|}{ Answer } & \multirow{2}{*}{ Mean } & \multirow[t]{2}{*}{ SD } & \multirow[t]{2}{*}{ Level** } \\
\hline & True* & False* & & & \\
\hline 1. Cervical cancer is the second most common cancer in women in Thailand. & $108(84.4)$ & $20(15.6)$ & 0.84 & 0.37 & high \\
\hline 2. Cervical cancer is caused by HPV viral infection. & $78(60.9)$ & $50(39.1)$ & 0.61 & 0.49 & moderate \\
\hline 3. Risk factor for cervical cancer includes women who have multiple partners. & $89(69.5)$ & $39(30.5)$ & 0.7 & 0.46 & high \\
\hline $\begin{array}{l}\text { 4. Being married to men who have multiple partners is considered } \\
\text { a risk factor for cervical cancer. }\end{array}$ & $70(54.7)$ & $58(45.3)$ & 0.55 & 0.5 & moderate \\
\hline 5. At present, Pap smear is used in cervical cancer screening in Thailand. & $116(90.6)$ & $12(9.4)$ & 0.91 & 0.29 & high \\
\hline 6. Women aged 21-65 years should be screened for cervical cancer. & $98(76.6)$ & $30(23.4)$ & 0.77 & 0.42 & high \\
\hline 7. Women should be screened for cervical cancer at least every 5 years. & $47(36.7)$ & $81(63.3)$ & 0.37 & 0.48 & moderate \\
\hline $\begin{array}{l}\text { 8. Even women who did not have children need to be screened } \\
\text { for cervical cancer. }\end{array}$ & $113(88.3)$ & $15(11.7)$ & 0.88 & 0.32 & high \\
\hline 9. Postpartum women should be screened for cervical cancer. & $117(91.4)$ & $11(8.6)$ & 0.91 & 0.28 & high \\
\hline 10. There is a vaccine to reduce the incidence of cervical cancer. & $54(42.2)$ & $74(57.8)$ & 0.42 & 0.49 & moderate \\
\hline Total & & & 0.7 & 0.412 & high \\
\hline
\end{tabular}

Table 3. Attitudes among VHVs Aboutcervicalcancer Screening (N=128)

\begin{tabular}{|c|c|c|c|c|c|c|c|c|}
\hline \multirow[t]{2}{*}{ Kttitude scores } & \multicolumn{8}{|c|}{ Attitude scale } \\
\hline & A & $\mathrm{B}$ & $\mathrm{C}$ & $\mathrm{D}$ & E & Mean & SD & Level \\
\hline 1. Cervical cancer can be cured if it is early detected & $73(57.0)$ & $42(32.8)$ & $12(9.4)$ & $1(0.8)$ & - & 4.46 & 0.69 & high \\
\hline 2. Pap smear is easy and painless & $56(43.8)$ & $58(45.3)$ & $14(10.9)$ & - & - & 4.33 & 0.66 & high \\
\hline \multicolumn{9}{|c|}{ 3. VHVs can provides knowledge about cervical cancer screening in the community accurately. } \\
\hline & & $58(45.3)$ & $21(16.4)$ & $3(2.3)$ & - & 4.15 & 0.77 & high \\
\hline Total & & & & & & 4.31 & 0.71 & high \\
\hline
\end{tabular}

VHVs: village health volunteers, Pap smear: Papanicolaou smears, standard deviation; A:strongly agree, B:agree, C: neither agree nor disagree, D: disagree, E: strongly disagree

Table 4. Percentage of Cervical Cancer Screening Coverage, Mean Scores of Knowledge, Attitudes and Percentages of Practices among VHVs

\begin{tabular}{|c|c|c|c|c|}
\hline \multicolumn{4}{|c|}{ District } & \multirow[b]{2}{*}{ p-value } \\
\hline A & B & $\mathrm{C}$ & $\mathrm{D}$ & \\
\hline \multicolumn{5}{|c|}{ Percentage of cervical cancer screening coverage } \\
\hline 62.4 & 34.7 & 80.3 & 47.3 & \\
\hline \multicolumn{5}{|c|}{ Mean of knowledge score(10 point) } \\
\hline 6.79 & 7 & 6.48 & 9 & $0.000 *$ \\
\hline \multicolumn{5}{|c|}{ Mean of attitude score( 15 point $)$} \\
\hline 12.4 & 13.17 & 13.36 & 13.08 & $0.043 *$ \\
\hline \multicolumn{5}{|c|}{ Percentage of practices } \\
\hline 72.2 & 94.3 & 94.9 & 50 & $0.000 *$ \\
\hline
\end{tabular}

*VHVs: village health volunteers A: KhlongYai, B: Chumphon, C: Bueng San, D: Suksara; *statistically significant $(\mathrm{p}<0.05)$

compliance rate was low. The locals mistrusted the health system because Srinakarinwirote University bought land to built its extended medical campus against the locals' plea to stay in the land of their for bearers. The locals did not trust the VHVs because they considered the VHVs as members of the health care regime and thus held hostility toward any service VHV offered. The hostility ruled over any health benefit VHV service could provide.

\section{Discussion}

In Thailand, women 30-60 years of age can take cervical cancer screening, Pap smear, with no out of the pocket cost from the health care center supported by the national policy promoting routine screening.One screening every five years bears no cost to the individual.
Sub-optimal participation is a major problem with cervical cancer screening in developing countries which have no organized national screening program. The Thai Public Health Office had set a cervical cancer screening goal according to the standard requirement that 80 percent of women aged 30-60 years-old should be screened by Pap test (2010-2014).

In Nakhonnayok province, cervical cancer screening coverage rate divided by 4 district Town, Ban Na, Ongkharak, Pak Phli district rate were 75.34, 83.75, 70.96 and 71.61, respectively. Three quarters of the districts had lower coverage rate than the specified goal. Ongkharak district, where the university is located, was divided into 4 sub districts namely Klong Yai, Chomphol, Buangsan and Suksara. Cervical cancer screening coverage were $62.4,34.7,80.3$ and 47.3 in those areas respectively. Data indicated that the coverage rates of screening of these places were low. Recent studies in Thailand found out that the passing informative knowledge about benefit of cervical cancer screeningby health care provider to the target population were the most important factor that bought target populations to receive screening services (Budkaewet al., 2014), (Wongwatcharanukul et al., 2014). But our study showed knowledge, health attitude and screening promotional practice of VHV had no association with cervical cancer screening coverage, especially among Thai Muslim group. This finding is similar to Chesun's study (Chesun et al., 2012). It reported that receiving a Pap test was found to be significantly higher amongThai Muslim women with a high level of perceived susceptibility, a low level of perceived barriers for the Pap test, having received a routine checkup, having received 
a recommendation by a doctor, health care personnel or husband. There was a lower chance of Pap test among women who had received a recommendation from village health volunteers (Chesun et al., 2012). Various notable factors namely as lack of time, embarrassment, low health attitude, mental conflict, social beliefs and socio-cultural practice were the barrier to compliance to cervical screening in the similar manner with other studies (Waller et al., 2009; Oranratanaphan et al., 2010; Baskaran et al., 2013; Schoueri-Mychasiw et al., 2013; Wongwatcharanukul et al., 2014). Social beliefs and socio-cultural practices were the most important barrier in Muslim women against cervical cancer screening. Associated health condition with the idea of 'God's will', cancer and other aspects of health would be accepted without any check up or prevention. Husband and family member attitudes were also a major barrier to receive a Pap test (Abdullahi et al., 2009; Srisakul et al., 2011; Chesun et al., 2012; Guimond et al., 2013).

In this Nakornnayok locality, even though VH s had in-depth knowledge and the right attitude to the promotion of cervical cancer screening, they could not encourage the Muslim women to receive cervical cancer screenings using what they know. In response to the Ministry of Public Health policy to covering cervical screening goal over $80 \%$ of the target population, mobile service, home screening, invitation letter, media campaigns, and direct mailed were used to increase cervical screening uptake during the last five years (2009-2014). The increase in screening coverage in Nakornnayok district was not significantly increased with all above efforts. Previous literatures found that employing a combination of multiple strategies was more likely to be successful than any single strategic interventions when the target population was ethnic Asian women (Chumworathayiel al., 2007; Lu et al., 2012). Mobile screening services and the combination of cultural awareness training for health care professionals with outreach workers who could help healthcare professionals to overcome language and cultural barriers were likely to improve cancer screening uptake. Home visit, invitation letter, media campaigns and mailed culturally sensitive print materials alone were be ineffective in increasing screening uptake. Any campaign executed by VHV should contain prior understanding of the target beliefs and socio-cultural condition. Strategies to increase coverage could include the training Muslim's outreach workers in encouraging target women to receive cervical cancer screening or the use of multimedia medium ethnically specific to the local belief could be introduced. Any effort to help family members especially husbands to understand the important of cervical cancer screening and supporting religious beliefs are also highly recommended.

In this study, there was no correlation between VHVs' knowledge, attitude and coverage rate for cervical cancer screening. Barriers to uptake of cervical cancer screening programs included self embarrassment, poor attitude, conflict, beliefs and socio-cultural reason. Even though VHV have a high knowledge and attitude to the promotion of cervical cancer screening, they cannot influence ethnic women to receive a cervical cancer screening. Therefore VHV should understand the target women 's socio-cultural beliefs. Improved strategies such as the use of Muslim staff or Muslim's outreach workers can be employed in encouraging target women to receive cervical cancer screening. Any effort to help family members especially husbands to understand the important of cervical cancer screening and supporting religious beliefs are also highly recommended.

\section{References}

Abdullahi A, Copping J, Kessel A, et al (2009). Cervical screening: Perceptions and barriers to uptake among Somali women in Camden. Public Health, 123, 680-5.

Baskaran P, Subramanian P, Rahman RA, et al (2013). Perceived susceptibility, and cervical cancer screening benefits and barriers in Malaysian women visiting outpatient clinics. Asian Pac J Cancer Prev, 14, 7693-9.

Budkaew J, Chumworathayi B, (2014). Factors associated with decisions to attend cervical cancer screening among women aged 30-60 years in Chatapadung Contracting Medical Unit, Thailand. Asian Pac J Cancer Prev, 15, 4903-7.

Chesun A, Harncharoen K, Taechaboonsermsak P, et al (2012). Factors related with cervical cancer screening test among Thai Muslim women in Satun province. Asia J Public Health, 3, 79-85.

Chumworathayi B, Yuenyao P, Luanratanakorn S, et al (2007). Can an appointment-letter intervention increase Pap smear screening in Samliem, Khon Kaen, Thailand? Asian Pac J Cancer Prev, 8, 353-6.

Guimond ME, Salman K (2013). Modesty matters: cultural sensitivity and cervical cancer prevention in Muslim women in the United States. Nurs Women's Health, 17, 210-6.

Lu M, Moritz S, Lorenzetti D, et al (2012). A systematic review of interventions to increase breast and cervical cancer screening uptake among Asian women. BMC Public Health, 12, 413 .

Oranratanaphan S, Amatyakul P, Iramaneerat K, et al (2010). Knowledge, attitudes and practices about the Pap smear among medical workers in Naresuan University Hospital, Thailand. Asian Pac J Cancer Prev, 11, 1727-30.

Schoueri-Mychasiw N, McDonald PW (2013). Factors associated with under screening for cervical cancer among women in Canada. Asian Pac J Cancer Prev, 14, 6445-50.

The Eleventh National Economic and Social Development Plan, 2012-2016, http://www.nesdb.go.th/Portals/0/news/plan/ p11/SummaryPlan11_Eng.pdf.

Waller J, Bartoszek M, Marlow L, et al (2009). Barriers to cervical cancer screening attendance in England: a population-based survey. J Med Screen, 16, 199-204.

Wilailak S (2009). Epidemiologic report of gynecologic cancer in Thailand. Gynecol Oncol, 20, 81-3. 